\title{
Investigating the Associations between Musculoskeletal Discomforts and Perceived Stress among Production Operators
}

\author{
Nor Hazana Abdullah,", Nor Aziati Abdul Hamid, Eta Wahab and Alina Shamsuddin \\ Department of Technology and Management, Faculty of Technology Management and Business, \\ Universiti Tun Hussein Malaysia, Parit Raja Batu Pahat, Johor 86400 Malaysia
}

\begin{abstract}
Both musculoskeletal pain and harmful stress have adverse health effects on production operators if they are not properly monitored or managed. However, the mechanism behind the association between these two variables is unclear especially when causal inference could not be deduced from majority of studies. Thus, there is a need for a better understanding of musculoskeletal pain and perceived stress among production workers in order to improve their health and safe working conditions. This is especially critical since majority of manufacturing companies in Malaysia are still labour intensive and any adverse effects of employees' health could impact the organizational performance. Therefore, the objective of this study is to determine the current prevalence of perceived stress and musculoskeletal pain among production workers and the possible linkage between perceived stress and musculoskeletal pain. A cross-sectional survey involving 400 shop-floor manufacturing workers was done using Cornell Musculoskeletal Discomfort Questionnaires (CMDQ) and Perceived Stress Questionnaires (PSQ). Data were analysed using hierarchal regressions. It is found that stress significantly affects MSDs albeit very weak $\left(\mathrm{R}^{2}=0.048\right)$ after controlling for gender and age. Neck, lower back and lower legs (Right and Left) were reported to have high prevalence of MSDs compared to other parts of the body $(\mathrm{M}=2.96$, $\mathrm{SD}=1.342 ; \mathrm{M}=2.72, \mathrm{SD}=1.441 ; \mathrm{M}(\mathrm{R})=2.6, \mathrm{SD}=1.418 ; \mathrm{M}(\mathrm{L})=2.63$, $\mathrm{SD}=1.415)$.
\end{abstract}

\section{Introduction}

Malaysia's Social Security Organization (SOCSO) statistics from year 1995 to 2009 has shown an exponential increase of cases in musculoskeletal disease from 5 cases (1995) to 161 cases in 2009 [1]. This trend continues as Borneo Post online reported that in 2010, there are 238 cases, followed by 268 cases in 2011 and 449 cases in 2012 [2]. Tan Sri Lee Lam claimed that such increase could be attributable to industrialization, aging workforce and lack of safety work practices at workplace [3]. Musculoskeletal diseases include injuries and illnesses that affect the human body's movement such as muscles, tendons, ligaments, nerves, discs, blood vessels, and many more. It is caused by ergonomics risk factors which include excessive force, repetition of movement or simply poor posture while working or risk factors which include poor work practices, poor fitness and poor health.

In similar vein, almost 70 percent of employees in Malaysia is claimed to experience escalated level of stress-related sickness [4] [5]. Failure to be adaptive to stress has ominous

\footnotetext{
* Corresponding author: hazana@uthm.edu.my
} 
consequences for both individuals and organizations [6] [7]. Individual who are unable to cope with the stress are incline to suffer psychological related illnesses such as depression, schizophrenia and anxiety disorders. Excessive stress not only undermines individual performance but could spill onto the organizational productivity and competitiveness. Studies have shown that MSDs and stress not only has an impact on productivity, but also on job satisfaction [8], [9], and other organizational outcomes. In a nutshell, stressful and unhealthy employees tend to have low workplace presence which leads to low productivity and commitment to work.

Medical literatures considered stress and an important factor in the onset and maintenance of widespread musculoskeletal pain (see for example [10]). McFarland [10], in particular, claimed that stress-musculoskeletal pain linkage could be either explained through neurophysiological, psychophysiological, cognitive-behavioural or geneticbehavioural mechanisms. The neurophysiological mechanism explains how pain causes stress response in the interconnected nervous system, endocrine system and immune system (e.g. [11] ) while psychophysiological highlights the impact of emotion and stress on pain (e.g. [12]. Cognitive-behavioural, on the other hand, emphasizes the roles of appraisals of danger, coping ability and choice of behaviour as causes of pain (e.g. [13]). Finally, genetic-behavioural regards each individual as having different threshold of pain and stress tolerance due to their genetics makeups (e.g. [14]).

As evidence from above-mentioned discussion, the stress-musculoskeletal pain linkage might have reciprocal causality rather than one-way cause and effect relationship. Inconsistent empirical evidence, which are mostly cross sectional in nature, limits our understanding and has led to much debates. . Moreover, since majority of these studies have been focusing on office employees [15], [16], farmers [17], laborer [18], medical staff [20][22], a study on manufacturing employees in developing country like Malaysia is warranted.. Das [17] further claimed that since both stress and MSDs are the two most common causes of work-related illnesses, there is a growing interest in their association, both in terms of common risk factors and the extent to which both are inter-related. Therefore, this study aimed to determine the current prevalence of perceived stress and musculoskeletal pain among production operators of manufacturing companies in Malaysia. The stress-musculoskeletal pain associations are also examined based on the psychophysiological mechanism. Specifically, we hypothesize the increase level of stress would increase musculoskeletal pain. Age and gender would be control variables in this study as the literatures have found that both variables could affect both musculoskeletal pain and stress [23]-[25].

Hans Seyle [30], the father of stress research, documented how stress affect the body in his 'General Adaptation Syndrome' (GAS) model. GAS consisted three phases called alarm reaction (Phase 1), resistance (Phase 2) and exhaustion (Phase 3). The alarm reactions activates physiological stress responses once the individual feel threatened. At this phase, individual's energy level and effectiveness is low due to the initial shocks. During the resistance phase, biochemical, psychological and behavioural mechanisms are activated to boost individual's ability to cope with the threat. If the cause of stress is not being eliminated or removed, the exhaustion phase commences where the immune system would deplete its ability to defend the system and individual is more likely to get sick. In the context of MCDs, muscles inevitably tense up in a reflect reaction against stressors and prolonged exposure to stress would cause the muscles to be in the prolonged state of guardedness. This will trigger illnesses such as headaches, migraine and muscle tensions in the area of shoulder, neck and head.

Schleifer [30] proposed hyperventilation theory of job stress where hyperventilation caused excessive loss of $\mathrm{CO} 2$ which in return increases the blood acidity level. This 
imbalance acidity level triggers a chain of systemic physiological reactions such as muscle tension and muscle spasm.

Several studies have shown empirical supports on the psychophysiological mechanisms of stress-musculoskeletal pain associations succinctly described by Seyle and Scheleifer. For example, Gonzales [25] found that stress is significantly related to MSDs across four companies being studies. Lin [15] further claim that despite women having higher prevalence of MSDs, encountering difficult customers is regarded as very stressful event that lead to increased risks of MSDs. Zakerian [16] added that work factors such as job demand, negative social interaction and computer-related problems contributed to stress which in turn, increased MSDs among computer users at university's office. Cheng [31] did a large scale study involving 26-25 years old Taiwanese and found that higher level of stress increased multiple health problems such as MSDs even after controlling for age and education.

\section{Methods}

This cross-sectional survey research included production operators working in eleven medium-sized manufacturing companies in the state of Johor, Malaysia. The selection of companies and their respective employees were done based on their agreement to participate. No personal data was recorded to maintain confidentiality and privacy. The data were collected in October and November 2016.

\subsection{Procedure}

Four hundred and twenty production operators participated in this study. The survey was collected face-to-face since to ensure that data were recorded correctly. However, ninetysix responses were excluded due to incomplete data as these respondents were unwilling to answer some questions.

Male respondents were slightly higher at $56.2 \%$ compared to female $(43.8 \%)$ with the majority of respondents aged between 23 to 27 years old $(31.2 \%)$ followed by those aged 28-32 years old (21.9\%). It could be concluded that more than $90 \%$ of the respondents aged below 42 years old. Majority of respondents $(79.6 \%)$ had worked more than 2 years. In terms of types of production tasks, $45.4 \%$ worked in packaging, $28.4 \%$ worked in quality assurance while $13 \%$ handled machines as shown in Table 1

Table 3. Respondents' Profiles

\begin{tabular}{|c|c|c|c|}
\hline \multicolumn{4}{|c|}{ Respondents' Profiles } \\
\hline \multirow[b]{2}{*}{ Gender } & & Freq & $\%$ \\
\hline & Male & 182 & 56.2 \\
\hline \multirow{7}{*}{ Age } & Female & 142 & 43.8 \\
\hline & $18-22$ years old & 42 & 13.0 \\
\hline & 23-27 years old & 101 & 31.2 \\
\hline & 28-32 years old & 71 & 21.9 \\
\hline & 33-37 years old & 46 & 14.2 \\
\hline & $38-42$ years old & 30 & 9.3 \\
\hline & Above 42 years old & 34 & 10.5 \\
\hline
\end{tabular}




\begin{tabular}{|c|c|c|c|}
\hline \multirow[t]{2}{*}{ Nationality } & Malaysian & 220 & 67.9 \\
\hline & Foreign & 104 & 32.1 \\
\hline \multirow{6}{*}{$\begin{array}{l}\text { Years of } \\
\text { Service }\end{array}$} & $<1$ year & 39 & 12.0 \\
\hline & 1 year & 27 & 8.3 \\
\hline & 2 years & 79 & 24.4 \\
\hline & 3 years & 57 & 17.6 \\
\hline & 4 years & 38 & 11.7 \\
\hline & $>4$ years & 84 & 25.9 \\
\hline \multirow{4}{*}{$\begin{array}{l}\text { Type of } \\
\text { Tasks }\end{array}$} & Packaging & 147 & 45.4 \\
\hline & Monitoring quality & 92 & 28.4 \\
\hline & Handling of machine & 42 & 13.0 \\
\hline & No response & 37 & 11.4 \\
\hline \multirow{6}{*}{$\begin{array}{l}\text { Hours of } \\
\text { Overtime }\end{array}$} & $0-2$ hours & 89 & 27.5 \\
\hline & $3-5$ hours & 78 & 24.1 \\
\hline & $6-8$ hours & 65 & 20.1 \\
\hline & 9-11 hours & 37 & 11.4 \\
\hline & $>11$ hours & 54 & 16.7 \\
\hline & No response & 1 & 0.3 \\
\hline \multirow{3}{*}{$\begin{array}{l}\text { Perceived } \\
\text { Stress }\end{array}$} & Low & 54 & 16.7 \\
\hline & Moderate & 249 & 76.9 \\
\hline & High & 21 & 6.5 \\
\hline
\end{tabular}

\subsection{Measures}

Cornell Musculoskeletal Discomfort Questionnaires was used to measure the musculoskeletal pain [32]. The questionnaires include hand assessment and total body assessment. Perceived Stress Questionnaires (PSQ) by Cohen was used to measure stress [33]. There were 10 items in the questionnaires with the scale being modified from 1-5 rather $0-4$. Both measurements had accepted reliabilities of more than 0.7 which are considered as acceptable [34].

\subsection{Analysis}

Both descriptive and hierarchical multiple regressions were used to analyse the data via the use of IBM SPSS Version 20.0. Descriptive analysis includes the tabulation of frequency, mean and SD. Prior to performing the hierarchical multiple regressions, assumptions such as linearity, multivariate normality, multi collinearity and homoscedasticity were examined. Upon satisfying all these assumptions, hierarchical multiple regressions were performed.

\section{Results}


Table 2 shows the frequency, mean, and standard deviation (SD) of musculoskeletal pain in terms of the frequency in the last work week. As evident from the Table 2, neck, lower back and lower legs (both left and right) have the highest frequency and mean of discomfort. Right hand is observed to have higher frequency of discomforts. This might imply that majority of respondent are right-handed. The prevalence areas of discomforts are consistent with previous studies such as [21][35] [36].

Table 3 shows the levels of discomfort. Highest frequency of 'Very Uncomfortable' was recorded for all these three areas. Similarly, Table 4 shows similar trend whereby all discomforts in all these three areas were reported to interfere with the respondents' abilities to perform their jobs.

Table 2. Frequency of Discomfort in Last Work Week

\begin{tabular}{|c|c|c|c|c|c|c|c|c|}
\hline & & \multicolumn{7}{|c|}{$\begin{array}{l}\text { During the last work week, how often did you experience ache, pain, discomfort in } \\
(\%) \text { : }\end{array}$} \\
\hline & & Never & $\begin{array}{l}\text { 1-2 times } \\
\text { last week }\end{array}$ & $\begin{array}{l}\text { 3-4 times } \\
\text { last week }\end{array}$ & $\begin{array}{l}\text { Once } \\
\text { every day }\end{array}$ & $\begin{array}{l}\text { Several Times } \\
\text { every day }\end{array}$ & Mean & SD \\
\hline \multirow{6}{*}{$\begin{array}{l}\text { RIGHT } \\
\text { HAND }\end{array}$} & Area A & 30.6 & 35.2 & 13.6 & 8 & 12 & 2.38 & 1.35 \\
\hline & Area B & 46.9 & 34.9 & 8.6 & 4.9 & 4.6 & 1.85 & 1.07 \\
\hline & Area $\mathrm{C}$ & 38 & 31.8 & 13.9 & 6.5 & 9.9 & 2.19 & 1.28 \\
\hline & Area D & 39.9 & 35 & 15.2 & 5.6 & 4.3 & 1.99 & 1.08 \\
\hline & Area E & 32.4 & 39.5 & 15.1 & 6.5 & 6.5 & 2.15 & 1.11 \\
\hline & Area F & 44.1 & 35.8 & 12.3 & 4.3 & 3.4 & 1.87 & 1.02 \\
\hline \multirow{24}{*}{$\begin{array}{l}\text { LEFT } \\
\text { HAND }\end{array}$} & Area A & 37.9 & 38.2 & 9.6 & 6.5 & 7.8 & 2.08 & 1.19 \\
\hline & Area B & 48.1 & 37 & 6.8 & 5.9 & 2.2 & 1.77 & 0.965 \\
\hline & Area $\mathrm{C}$ & 38.6 & 25.3 & 17.8 & 9.4 & 8.8 & 2.24 & 1.294 \\
\hline & Area D & 40.7 & 36.3 & 12.7 & 6.8 & 3.4 & 1.96 & 1.057 \\
\hline & Area E & 40.3 & 33.1 & 12.8 & 9.1 & 4.7 & 2.05 & 1.148 \\
\hline & Area F & 46.3 & 28 & 14.3 & 4 & 7.5 & 1.98 & 1.201 \\
\hline & Neck & 14.5 & 28.1 & 24.1 & 13.3 & 20.1 & 2.96 & 1.342 \\
\hline & Shoulder (Right) & 17.8 & 42.4 & 13.1 & 11.8 & 15 & 2.64 & 1.314 \\
\hline & Shoulder (Left) & 17 & 39.4 & 18.3 & 9.8 & 15.5 & 2.67 & 1.3 \\
\hline & Upper Back & 25.3 & 29 & 16.7 & 15.4 & 13.6 & 2.63 & 1.367 \\
\hline & Upper Arm(Right) & 35.8 & 29.6 & 18.2 & 8.3 & 8 & 2.23 & 1.244 \\
\hline & Upper Arm (Left) & 34.7 & 31.6 & 18.4 & 8.1 & 7.2 & 2.22 & 1.209 \\
\hline & Lower Back & 24.1 & 29.4 & 16.1 & 10.8 & 19.5 & 2.72 & 1.441 \\
\hline & Forearm (Right) & 35.8 & 29.6 & 18.2 & 8.3 & 8 & 2.27 & 1.23 \\
\hline & Forearm (Left) & 34.7 & 31.6 & 18.4 & 8.1 & 7.2 & 2.27 & 1.248 \\
\hline & Wrist (Right) & 31.3 & 34.1 & 13.6 & 7.7 & 13.3 & 2.38 & 1.349 \\
\hline & Wrist (Left) & 31.9 & 33.1 & 13.9 & 8.4 & 12.7 & 2.37 & 1.343 \\
\hline & Hip & 39.4 & 25.9 & 14.7 & 7.8 & 12.2 & 2.38 & 1.371 \\
\hline & Thigh (Right) & 35.8 & 25 & 18.2 & 11.4 & 9.6 & 2.34 & 1.322 \\
\hline & Thigh (Left) & 35.9 & 24.4 & 20.6 & 10 & 9.1 & 2.32 & 1.64 \\
\hline & Knee (Right) & 26.5 & 37.7 & 16 & 9.9 & 9.9 & 2.39 & 1.25 \\
\hline & Knee (Left) & 26.7 & 37 & 17.4 & 9.9 & 9 & 2.38 & 1.23 \\
\hline & Lower Leg (Right & 25.9 & 33 & 13.3 & 10.5 & 17.3 & 2.6 & 1.418 \\
\hline & Lower Leg (Left) & 25.2 & 32.4 & 13.7 & 11.5 & 17.1 & 2.63 & 1.415 \\
\hline
\end{tabular}


Table 3. Levels of Discomfort

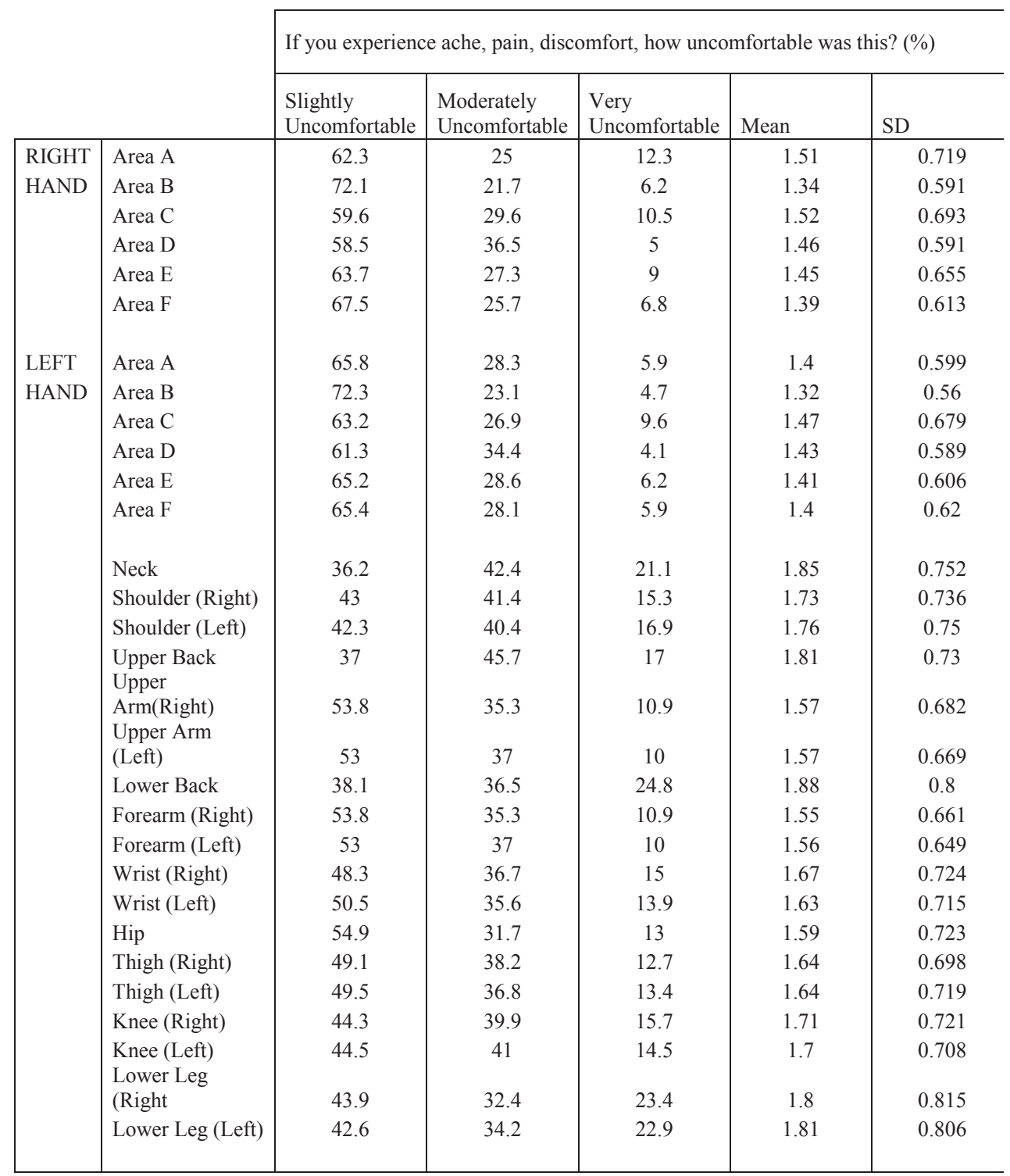


Table 4. Level of Interference with Work

\begin{tabular}{|c|c|c|c|c|c|c|}
\hline & & \multicolumn{5}{|c|}{$\begin{array}{l}\text { If you experience ache, pain, discomfort, did this interfere with your ability to } \\
\text { work? }(\%)\end{array}$} \\
\hline & & Not at all & $\begin{array}{l}\text { Slightly } \\
\text { Interfered }\end{array}$ & $\begin{array}{l}\text { Substantially } \\
\text { Interefered }\end{array}$ & Mean & SD \\
\hline \multirow{6}{*}{$\begin{array}{l}\text { RIGHT } \\
\text { HAND }\end{array}$} & Area A & 45.1 & 39.8 & 14.5 & 1.7 & 0.722 \\
\hline & Area B & 59 & 32 & 8.7 & 1.51 & 0.68 \\
\hline & Area C & 47.1 & 39 & 13.3 & 1.68 & 0.736 \\
\hline & Area D & 48.5 & 43.5 & 7.7 & 1.6 & 0.644 \\
\hline & Area $\mathrm{E}$ & 45.4 & 42.9 & 11.4 & 1.67 & 0.686 \\
\hline & Area F & 53.9 & 36.8 & 9.3 & 1.55 & 0.659 \\
\hline \multirow{24}{*}{$\begin{array}{l}\text { LEFT } \\
\text { HAND }\end{array}$} & Area A & 50.3 & 42.2 & 7.5 & 1.57 & 0.629 \\
\hline & Area B & 63.6 & 31.5 & 5 & 1.41 & 0.586 \\
\hline & Area $\mathrm{C}$ & 48.1 & 38.2 & 13.7 & 1.66 & 0.708 \\
\hline & Area D & 51.9 & 42.2 & 5.9 & 1.54 & 0.607 \\
\hline & Area E & 50.2 & 38.3 & 11.5 & 1.61 & 0.685 \\
\hline & Area F & 52.8 & 35.4 & 7.8 & 1.51 & 0.638 \\
\hline & Neck & 30.6 & 46.6 & 22.8 & 1.92 & 0.728 \\
\hline & Shoulder (Right) & 33.7 & 48.4 & 17.9 & 1.84 & 0.702 \\
\hline & Shoulder (Left) & 37.4 & 43.1 & 19.5 & 1.82 & 0.734 \\
\hline & $\begin{array}{l}\text { Upper Back } \\
\text { Upper }\end{array}$ & 35.2 & 5.06 & 14.2 & 1.79 & 0.672 \\
\hline & Arm(Right) & 50.2 & 41.2 & 8.7 & 1.59 & 0.646 \\
\hline & $\begin{array}{l}\text { Upper Arm } \\
\text { (Left) }\end{array}$ & 50.3 & 41.3 & 8.4 & 1.58 & 0.643 \\
\hline & Lower Back & 31 & 48.6 & 20.4 & 1.89 & 0.71 \\
\hline & Forearm (Right) & 50.2 & 41.2 & 8.7 & 1.64 & 0.695 \\
\hline & Forearm (Left) & 50.3 & 41.3 & 8.4 & 1.62 & 0.686 \\
\hline & Wrist (Right) & 43.9 & 40.2 & 15.6 & 1.72 & 0.73 \\
\hline & Wrist (Left) & 44.2 & 41.7 & 14.1 & 1.7 & 0.703 \\
\hline & Hip & 46.9 & 39.3 & 13.8 & 1.67 & 0.707 \\
\hline & Thigh (Right) & 44.8 & 40.1 & 15.1 & 1.7 & 0.716 \\
\hline & Thigh (Left) & 44.7 & 41.3 & 13.7 & 1.7 & 0.711 \\
\hline & Knee (Right) & 36.6 & 44.7 & 18.8 & 1.82 & 0.723 \\
\hline & Knee (Left) & 34.4 & 49.7 & 15.9 & 1.82 & 0.686 \\
\hline & $\begin{array}{l}\text { Lower Leg } \\
\text { (Right }\end{array}$ & 36.3 & 37.9 & 25.5 & 1.9 & 0.799 \\
\hline & Lower Leg (Left) & 36.3 & 38.8 & 24.5 & 1.89 & 0.792 \\
\hline
\end{tabular}

Table 5 shows the hierarchical regression analysis on the effect of stress on MSDs. In the first model, age and gender were regressed against MSDs as control variables. The model is significant albeit very weak at $\mathrm{R}^{2}=0.02$. In the second model, stress was regressed together and it is found that stress had significant role in prediction of MSDs. However, in terms of $\mathrm{R}^{2}$, the value is still small at $4.8 \%$. Whether this value has practical significance certainly could be debated. 
Table 5. Summary of Hierarchical Regression Analysis for Predicting MSDs (N-324)

\begin{tabular}{|c|c|c|c|c|c|c|c|}
\hline \multirow[b]{2}{*}{ Variable } & & \multicolumn{3}{|c|}{ Model 1} & \multicolumn{3}{|c|}{ Model 2} \\
\hline & & $\mathrm{B}$ & SE B & $\beta$ & $\mathrm{B}$ & SE B & $\beta$ \\
\hline Age & & 0.027 & 0.17 & 0.087 & 0.027 & 0.017 & -0.085 \\
\hline Gender & & 0.105 & 0.053 & 0.109 & 0.091 & 0.052 & 0.094 \\
\hline Stress & & & & & 0.187 & 0.046 & 0.220 \\
\hline$R^{2}$ & & & 0.02 & & & 0.048 & \\
\hline $\begin{array}{l}\mathrm{F} \text { for } \\
\text { change in }\end{array}$ & $R^{2}$ & & $3.265^{*}$ & & & $16.472 * *$ & \\
\hline
\end{tabular}

\section{Discussions}

The results clearly indicate neck, lower back and lower legs scored highly in terms of frequency of discomforts, extent of discomforts and level of discomforts' interference with the abilities to perform the jobs. The prevalence of MSDs at these areas might indicate the poor ergonomics working conditions of manual labour in participating companies. Furthermore, all of these respondents are not stationary while working, and might be involved in frequent lifting task that significantly impacted low back pain [35]. Da Costa and Vieira [37] claimed that heavy physical work, awkward postures, lifting and whole body vibration Lower legs discomforts might imply excessive standing of prolonged hours. Interestingly, neck pain is also a common discomfort in this study as being reported in studies of other types of occupations [36]. According to Matsudaira [38], neck and shoulder discomfort or katakori in Japanese is common among Japanese adults and might lead to somatization.

The regression result indicates that stress is an important consideration to reduce MSDs but the practical significance in this study is very small despite majority of respondents reported moderate level of stress $(76.9 \%)$. Contrary to previous studies that highlight the significant moderate effect of stress on MSDs, this study indicates the presence of other risk factors. Moreover, since this study control for age and gender while others usually investigate direct relationship, this result is expected. Therefore, further replication of this study with inclusion of other risk factors might be needed.

\section{Conclusions}

Production operators experienced musculoskeletal discomforts at neck, lower back and lower legs. This is consistent with the nature of the production activities which are still largely manual and repetitive. Majority of them experienced moderate level of stress with $6.5 \%$ experience high level of stress. There is a significant but very weak association between stress and MSDs when gender and age were controlled. 
This study is not without limitation. As the nature of this study is cross-sectional, causality inference is cautioned. Furthermore, all measures are based on employees' perceptions However, it is important to note that self-rating predicts better compared to objective measurement. Furthermore, subjective measures are also more widely use and easy to assess.

\section{References}

1. DOSH, [Online]. Available: http://www.dosh.gov.my/index.php/en/list-ofdocuments/statistics-socso/330-occupational-musculoskeletal-diseases-statistics1995-2009/file. [Accessed: 19-Jun-2017].

2. P. Boon, BorneoPost Online | Borneo, Malaysia, Sarawak Daily News | Largest English Daily In Borneo," Borneo Post Online, 2013. [Online]. Available: http://www.theborneopost.com/2013/01/28/musculoskeletal-disease-increasecause-for-concern/. [Accessed: 19-Jun-2017].

3. Lee Lam Thye, NST Online, 2016. [Online]. Available: https://www.nst.com.my/news/2016/04/142074/work-stress-and-mental-health. [Accessed: 20-Jun-2017].

4. Ain Ruzanna, Business Insider, 2014. [Online]. Available: http://www.businessinsider.my/scary-statistics-stress-silentkiller/\#LXsZSHQGImbEYdr1.97. [Accessed: 20-Jun-2017].

5. A. Dewan, | Human Resources Online," Human Resources, 2013. [Online]. Available: http://www.humanresourcesonline.net/majority-malaysians-suffer-workrelated-stress/. [Accessed: 20-Jun-2017].

6. P. K. Wilke, W. H. Gmelch, and N. P. Lovrich, Public Product. Rev., 9, 4, pp. $342-$ $356,1985$.

7. Jex and S. M., Sage Publications Ltd, 1998.

8. K. Fairbrother and J. Warn, J. Manag. Psychol., 18, 1, pp. 8-21, 2003.

9. I. Maakip, T. Keegel, and J. Oakman, J. Occup. Rehabil., 25, 4, 2015.

10. A. C. McFarlane, Best Pract. Res. Clin. Rheumatol., 21, 3, pp. 549-565, Jun. 2007.

11. C. L. Cooper, Career Dev. Int., 10, 5, pp. 396-399, Aug. 2005.

12. M. J. Sanders and C. M. Turcotte, Work, 35, 4, 2010.

13. H. Busch, Scand. J. Caring Sci., 19, 4, 2005.

14. K. Ekberg, J. Eklund, M.-A. Tuvesson, R. Örtengren, P. Odenrick, and M. Ericson, Work Stress, 9, 4, 1995.

15. Y.-H. Lin, C.-Y. Chen, and S.-Y. Lu, Appl. Ergon., 40, 4, 2009.

16. S. Zakerian and I. D. Subramaniam, Int. J. Occup. Saf. Ergon., 15, 4, 2009.

17. B. Das and S. Gangopadhyay, Asia-Pacific J. Public Heal., 27, 2, 2015.

18. T. Ghosh, B. Das, and S. Gangopadhyay, Indian J. Community Med., 35, 2, 2010.

19. B. Das, ”Int. J. Occup. Med. Environ. Health, 27, 3, 2014.

20. H. Abdul Rahman, K. Abdul-Mumin, and L. Naing, Asian Nurs. Res. (Korean. Soc. Nurs. Sci)., 11, 1, 2017.

21. K. Azma, A. Hosseini, M. H. Safarian, and M. Abedi, N. Am. J. Med. Sci., 7, 7, 2015.

22. Y.-K. Kong, D.-M. Kim, K.-S. Lee, and M.-C. Jung, Appl. Ergon., 43, 2, 2012.

23. C. R. Palliser, H. M. Firth, A. M. Feyer, and S. M. Paulin, Work Stress, 19,. 4, 2005.

24. L. E. Rocha and M. Debert-Ribeiro, Rev. Saude Publica, 35, 6, 2001.

25. E. L. González-Muñoz and R. Á. ChaurandProcedia Manuf., 3, 2015.

26. N. Fold and A. Wangel, "Geografisk tidskrift," in Geografisk Tidsskrift, 97, Kongelige danske geografiske selskabet, 1997. 
27. "Ergonomics Guidebook for Manual Production Systems."

28. H. S. Loo and S. Richardson, J. Soc. Sci., 8, 1, pp. 61-65, 2012.

29. Z. M. Makhbul, Int. J. Acad. Res. Bus. Soc. Sci., 3, 1, pp. 183-195, 2013.

30. H. Selye, Annu. Rev. Med., 2, 1, pp. 327-342, Feb. 1951.

31. Y. Cheng, Y.-L. Guo, and W.-Y. Yeh, Int. Arch. Occup. Environ. Health, 74, 7, 2001.

32. A. Hedge, S. Morimoto, and D. McCrobie, Ergonomics, 42, 10, pp. 1333-1349, 1999.

33. S. Cohen, T. Karmack, and R. Mermelstein, J. Health Soc. Behav., 24, pp. 386396, 1983.

34. J. C. Nunnally, Psychometric theory, 2nd ed. New York: McGraw-Hill, 1978.

35. A. M. Basahel, Procedia Manuf., 3, 2015.

36. E. Pék, B. Bánfai, K. Deutsch, S. Jeges, and J. Betlehem, Lege Artis Med., 24, 1011, 2014.

37. B. R. Da Costa and E. R. Vieira, Am. J. Ind. Med. J . Ind . Med, 53, 53, pp. 285323, 2010.

38. K. Matsudaira, H. Konishi, K. Miyoshi, T. Isomura, and K. Inuzuka, PLoS One, 9, 4, p. e93924, 2014. 